\title{
La integración social de los hijos de inmigrantes africanos, europeos del este y latinoamericanos: un estudio de caso en España*
}

Social Integration of Children of Immigrant Parents from Africa, Eastern Europe and Latin America: a Case Report in Spain

Recibido: 15 de mayo de 2012 | Revisado: 6 de octubre de 2014 | Aceptado: 11 de mayo de 2014

\author{
JuAn CARlos CheCA ** \\ Universidad de Almería, Almería, España \\ MONTSERRAT MONSERRAT **** \\ Centro de Estudios Migratorios y de Relaciones \\ Interculturales, Almería, España
}

doi:10.11144/Javeriana.upsy14-2.lish

Para citar este artículo: Checa, J., \& Monserrat, M. (2015). La integración social de los hijos de inmigrantes africanos, europeos del este y latinoamericanos: un estudio de caso en España. Universitas Psychologica, 14(2), 475-486. http://dx.doi. org.10.11144/Javeriana.upsy14-2.lish

* Agradecimientos. Este texto es fruto del proyecto "La integración de los jóvenes inmigrantes en España. El caso almeriense", subvencionado por el Centro de Estudios de Migraciones y Relaciones Interculturales (Cemyri).

** Profesor Titular de Universidad. Área de Sociología. Contacto principal para correspondencia editorial. Correo electrónico: jcheca@ual.es

**** Investigadora del Centro de Estudios Migratorios y de Relaciones Interculturales. Almería, España. Correo electrónico:mm2010ual@gmail.com

\section{RESUMEN}

El objetivo principal de este artículo fue estudiar el proceso de integración social en Almería (España) de hijos de inmigrantes, llegados de África, Latinoamérica y Europa del Este. Se estudió la integración social a partir de las siguientes dimensiones: aspectos socioeconómicos, relaciones mixtas, referentes culturales, normas, transnacionalidad y factor psicosocial. Los datos se obtuvieron a partir de la administración de una encuesta. Los resultados muestran que el origen es una variable fundamental a la hora de definir la integración social. También, aparecen otras variables importantes que definen el proceso de integración de los inmigrados, como son el capital humano, el entorno o los patrones religiosos. Esta variedad de elementos que intervienen en la integración permite afirmar que esta se está produciendo en Almería de manera fragmentada y no responde a un proceso lineal.

Palabras clave

asimilación segmentada; jóvenes inmigrantes; segunda generación

\section{A B S T R A C T}

The aim of this paper is to study the social integration process of children of immigrants from Africa, Latin America and Eastern Europe in Almería (Spain). We study the social integration process in the following dimensions: socioeconomic, mixed relationships, cultural references, norms (rules of conduct), transnationality and psychosocial factors. Data were obtained by the administration of a questionnaire. The results show that the origin is a key variable in defining the social integration process. Furthermore there are other important variables that affect the integration process of immigrants, such as human capital, the (social) environment or religious patterns. Taking into account the variety of elements involved in the integration of immigrants in Almeria, we would speak of integration as a fragmented process which doesn't reflect any linear logic.

Keywords

segmented assimilation; young immigrants; second generation 


\section{Introducción}

En las ciencias sociales la integración social de los inmigrados ha sido una de las temáticas de análisis más abordada, generando un vasto corpus teórico y empírico. En las últimas décadas el foco de atención se ha centrado en el estudio de la integración de los jóvenes inmigrantes pertenecientes a la segunda y siguientes generaciones ${ }^{1}$.

Durante gran parte del siglo pasado, en la literatura internacional ha dominado la filosofía asimilacionista (Alba 2005; Alba \& Nee 1997; Gordon 1964; Park, 1928). Entendida esta como una propuesta de uniformización cultural mediante la cual se propone -y supone- que los grupos y minorías van adoptando la lengua, los valores, las normas y las señas de identidad de la cultura dominante y, en paralelo, abandonan su cultura propia. Gordon (1964) fue el autor que más analizó este proceso estableciendo varias etapas: $1^{\text {o) }}$ ) adquisición de las pautas culturales del grupo mayoritario, desde el lenguaje o formas de vestir hasta valores más profundos como son la identidad o religión; $2^{\underline{9}}$ ) asimilación estructural: los inmigrantes establecen relaciones de tipo primario con los autóctonos, hasta el punto que la discriminación desaparece y los inmigrantes se introducen en todas las instituciones -clubes, asociaciones, matrimonios mixtos, etc.-, de manera que se produce una pérdida de sus características distintivas y dejan de existir como grupos y $3^{\circ}$ ) formación de una identidad común, a partir de la consolidación de unos sentimientos de pertenencia a un mismo destino, que la cultura de llegada dicta, a la vez que se produce una ausencia de valores y de fuerzas políticas conflictivas, produciéndose, en este caso, la asimilación cívica.

En la década de 1960, en Estados Unidos, esta comprensión clásica de la asimilación se modificó

1 García $(2003$; 2008) realiza una crítica al concepto de inmigrantes de segunda generación $-y$ siguientes generaciones $-y$ a su dificultad de operacionalización científica, puesto que no faltan ocasiones en las que su formulación aparece como estigmatizante y en oposición a lo autóctono (inmigrante segunda generación vs. nacional) y cuya consecuencia es la fractura identitaria y desarraigo cultural, olvidando que son sujetos que nunca han migrado, y es en destino donde se produce su socialización, tal y como ocurre con los nacionales. debido a la llegada de inmigrantes no europeos latinos y asiáticos, principalmente-, los cuales en lugar de reproducir la convergencia prevista y la asimilación total en el seno de la sociedad receptora, se apreció un mantenimiento de las diferencias étnicas a través de las generaciones (Zhou, 1997). Tomando en cuenta esto, Portes (1995) desarrolló la teoría de la asimilación segmentada, para intentar explicar por qué los nuevos inmigrantes y sus descendientes adoptan diferentes itinerarios de integración con respecto a los grupos poblacionales asentados previamente. Su planteamiento parte de la premisa de que la inclusión de los inmigrantes depende del sistema de estratificación de la sociedad anfitriona y de las características del grupo, cuya combinación tendrá como resultado tres diferentes estrategias tomadas por parte de los inmigrados: 1) aculturación e integración en la clase media del país que coincide con la concepción clásica de la asimilación; 2) situación de pobreza permanente y asimilación en la clase baja y 3) a pesar de un posible progreso económico, se opta por la preservación deliberada de los valores propios y de origen a través de redes sociales comunitarias y el sostenimiento de la solidaridad intragrupal (selective acculturation). A raíz de ello, se habla de consonant acculturation si los hijos experimentan un proceso similar al de los padres y dissonant acculturation si es diferente.

No obstante, en este modelo también se vislumbran ciertas lagunas a la hora de aplicarlo al contexto europeo: las formas de observar e intervenir en la integración son diferentes en función del país (Levitt \& Glick Schiller, 2004; Thomson \& Crul, 2007); también la filosofía del sistema educativo de cada país (Crul \& Vermeulen, 2003) y sus medidas, a la hora de plantear respuestas ante los retos migratorios hacen diferentes los procesos de integración (Carrera, 2006; Zapata, 2009) y por último, que las trayectorias que pueden tomar los inmigrados en su proceso de integración son más de tres, ya que el supuesto inicial no había tenido en cuenta la combinación de todos los escenarios socioeconómicos posibles con las diferentes estrategias de aculturación. Por todo ello, en Europa se prefiere hablar mejor de pluralismo fragmentado (Checa \& Arjona, 2009; Hartmann \& Gerteis, 
2005), poniendo de relieve los, casi incalculables, caminos y trayectorias que siguen los inmigrados a la hora de insertarse en destino.

En España, a pesar de lo incipiente del fenómeno de segunda generación de inmigrantes ${ }^{2}$, está apareciendo un número importante de investigaciones al respecto (véanse, entre otros, Aparicio, 2007; Aparicio \& Portes, 2014; Arjona, Checa, \& Belmonte, 2011; Checa \& Arjona, 2009; Gualda, 2007, 2008, 2010; Portes, Aparicio, Haller, \& Vickstrom, 2010; Portes, Celaya, Vickstron, \& Aparicio, 2012), las cuales superan los primeros análisis que se centraban principalmente en la inserción de los jóvenes en el sistema educativo (Franzé, 2003; Franzé, Moscoso, \& Calvo, 2010), puesto que hacen especial hincapié en sus trayectorias identitarias como actores sociales, (véanse, entre otros, Colectivo Ióe et al., 2009; Echeverri, 2005; 2011; 2012, Carrasquilla \& Echeverri, 2003; Pedone, 2007). En las que los inmigrados se encuentran "atrapados" entre la autoidentificación con origen, con destino, supranacional o heteroidentidad (Colectivo Ioé, Actis, De Prada, \& Pereda, 2009).

Con la pretensión de seguir en esta línea de investigación, el objetivo de este texto es analizar el grado de asimilación de los inmigrados, residentes en Almería ${ }^{3}$ (España), en las diferentes dimensiones que definen la integración social: socioeconómica, referentes culturales, normas y relaciones mixtas (Safi, 2006; 2008), transnacionalidad y cuestiones psicosociales (Aparicio \& Portes, 2014; Gualda, 2010; Portes et al., 2010; Safi, 2010).

Ahora bien, lo novedoso de este trabajo es el uso y aplicación de elementos teóricos y metodológicos, diseñados para explicar el fenómeno de la integración social en ámbitos macro, en contextos locales o micro, puesto que compartimos la idea de Gual-

2 Según el INE, en 1998 había 56.890 hijos de inmigrantes nacidos en España. En 2010 el número había aumentado hasta los 364.392. Por su lado, Almería, para esos mismos años, ha pasado de 396 a 10.306.

3 El porcentaje de población extranjera asciende al $22.1 \%$. En el último año, al contrario del resto de España, Almería ha experimentado un aumento de 3.883 inmigrantes, alcanzando la cifra de 155.042. Una de sus principales características es su juventud, la suma de extranjeros menores de 30 años representa el $41.4 \%$ del total. da (2007) cuando hace un llamamiento a prestar atención a las particularidades de integración de los inmigrantes en ámbitos locales.

\section{Método}

\section{Participantes}

Se ha tomado como universo a la población inmigrante latinoamericana, europea del este y africana, entre 12 y 18 años, matriculada en el curso académico 2010-2011 en tres centros de enseñanza secundaria pública, situados en municipios de alta recepción de inmigrantes (más del $20 \%$ de su población total) de la provincia de Almería. En total, el universo y la muestra abarca 155 sujetos, de los cuales el $45.8 \%$ son mujeres y el $54.2 \%$, hombres. La edad media es de 14.84 años $(D E=1.58)$. En cuanto a la generación ${ }^{4}$, el grueso de la muestra se concentra en la generación 1.5 (52 \%) y la 1.75 (22\%).

\section{Instrumento y variables}

Los resultados se obtuvieron a partir de la administración de una encuesta. En la elaboración del cuestionario hemos tomado como referencia, principalmente, Mobilité Géographique et Insertion Sociale (MGIS) empleada por Tribalat (1996) en el estudio de la integración de los inmigrantes en Francia. A partir de este cuestionario, se seleccionaron, primero, los indicadores empleados por Safi (2006; 2008) a la hora de medir la integración de los inmigrantes de segunda generación en Francia: socioeconomía, referentes culturales, normas y relaciones mixtas. Segundo, Checa y Arjona (2009), además de las anteriores dimensiones, añaden la

4 Para construir los diferentes subgrupos generacionales redefinimos y ampliamos, para adecuarlo a nuestro contexto, la clasificación dictada por Portes y Rumbaut (2010): hijos de inmigrantes nacidos en Almería ("segunda generación pura"); hijos de inmigrantes nacidos en origen llegados a España con edades comprendidas entre 0 y 5 años ("generación 1.75 "); los nacidos en origen y llegados a España con sus padres con menos de 12 y más de 6 años ("generación 1.5"); y los hijos de inmigrantes nacidos en el extranjero que llegan a España con sus padres con más de 12 años y menos de 18 ("generación 1.25"). 
transnacionalidad. Y tercero, los trabajos de Gualda (2010), Portes et al. (2010) o Safi (2010) abordan cuestiones psicosociales, entendiéndolas como una dimensión global en la que el sujeto evalúa, de manera general, su proceso de integración.

En cualquier caso, la operacionalización y construcción de las dimensiones se realizaron siguiendo el procedimiento diseñado por Safi (2006; 2008), así: se adjudica el valor uno a aquellas alternativas de respuesta de cada una de las dimensiones que son más cercanas a lo que presenta, de manera general, la población autóctona, y el valor cero en los casos contrarios. De tal forma que, como resultado de cada dimensión, el índice oscila entre 0 y 4, considerándose una mayor asimilación en cada dimensión conforme los resultados se van acercando al valor 4. A continuación, se muestra de manera más detallada la construcción de cada índice:

1) Dimensión socioeconómica: compuesta, en primer lugar, por el régimen de tenencia de la vivienda ( 1 = "Propiedad"); en segundo lugar, el nivel de ingresos mensuales ( 1 = "Más de 1.000 euros"); en tercer lugar, la clase social subjetiva $(1=$ "Alta" y "Media alta") y por último, situación laboral del padre ( 1 = "Trabaja actualmente").

2) Dimensión relacional: relaciones mixtas $(1=$ "Todos sus amigos son españoles" o "La mayoría de sus amigos son españoles"); en segundo lugar, persona a la que persona acude cuando tiene un problema ( 1 = "A un amigo español"); tercero, la nacionalidad de su pareja actual o, en caso de no tenerla, la que le gustaría que fuera ( 1 = "Española") y, por último, el lugar donde le gustaría vivir $(1=$ "En barrios de mayoría española" o "Barrios de extranjeros y españoles con igual proporción”).

3) Dimensión referentes culturales: en su composición se han tenido en cuenta, primero, el idioma en el que desearía educar a sus hijos ( 1 = "En español"); segundo, pautas religiosas en las que desearía educar a sus hijos (1 = "En la de destino"); tercero, en relación con el uso del tiempo libre, se indaga por el tipo de música que, principalmente, escucha (1 = "Grupos y/o música española") y, por último, el tipo de gastronomía que degusta habitualmente ( 1 = "Típica española").
4) Dimensión normas: su construcción depende, primero, de la importancia de identificarse con su religión y prácticas ( 1 = "Nada" o "Poco"); segundo, el número de hijos que quiere tener $(1=$ "Dos hijos o menos"); tercero, el nivel educativo deseado (1 = "Carrera universitaria") y, por último, valoración de la participación de la mujer en el mercado laboral ( 1 = "Totalmente de acuerdo" y "Bastante de acuerdo").

5) Transnacionalidad: se toma como referencia, en primer lugar, la frecuencia de contacto con familiares o amigos en el país de origen ( $1=$ "Nada" o "Poco"); en segundo lugar, las remesas monetarias ( 1 = "Nunca envía dinero" -él o su familia-); en tercer lugar, el interés mostrado por los problemas políticos y socioeconómicos de origen $(1=$ interés "Nulo" o "Bajo") y, en cuarto lugar, la idea de retorno a origen (1 = "Nunca").

6) Factor psicosocial: esta dimensión ha quedado conformada a partir del sentimiento de integración en la sociedad española $(1=$ "Bastante" o "Mucho"); del grado de felicidad con la vida (1 = "Me siento muy feliz"); del grado de satisfacción con el lugar que vive ( 1 = "Totalmente satisfecho" y "Muy satisfecho") y, por último, de la autoidentificación (1 = "Exclusivamente como español").

De igual modo, en el análisis vamos a insertar como factores independientes, tanto variables demográficas: edad, sexo $(1=$ hombre), origen (ref. países de Europa del este), tiempo de estancia en España (1 = más de 5 años) y generación (ref. generación 1.75); como contextuales: ámbito residencial ( 1 = mayoría de vecinos españoles), estructura familiar en el país de acogida ( 1 = estructura similar a la media española ${ }^{5}$ ) e individuales: situación jurídica del cabeza de familia $(1=$ doble nacionalidad o nacionalidad española), profesión del cabeza de familia ( 1 = empleo de cuello blanco), posesión del padre de estudios superiores $(1=$ estudios universi-

5 Según datos del INE para el 2011, la tasa media de natalidad se encuentra en 1.39 hijos por mujer. Asimismo, el término familia nuclear se usa para designar una unidad familiar formada por los miembros de una pareja y sus hijos no casados -si los hay-, o por un adulto y sus hijos. Por tanto, atendiendo a esto, la estructura familiar típica/mayoritaria española es nuclear y como máximo con 2 hijos. 
tarios o de postgrado) y religión ( 1 = católica $)$, competencias comunicativas en español $(1=$ perfecto $)$.

\section{Procedimiento}

Los centros de enseñanza secundaria seleccionados corresponden a tres de aquellos que, según la Delegación de Educación de Almería, presentan altas concentraciones de inmigrantes. La administración del cuestionario correspondió a todos los alumnos extranjeros presentes ese día -con los orígenes preestablecidos- en cada centro seleccionado, desde primero hasta cuarto de la ESO.

En los primeros cursos de la ESO (menores de 14 años), para evitar obtener demasiados cuestionarios no válidos, se decidió administrar el cuestionario de forma conjunta, es decir, dictando las preguntas en voz alta para toda la clase y los encuestados contestando de forma particular, anónima y en silencio; cuando surgía alguna duda se resolvía de forma individual, para no condicionar las respuestas de los compañeros. Para el alumnado que llevaba poco tiempo en España y no presentaba las competencias comunicativas suficientes, se le pasaba el cuestionario en privado, adecuando el lenguaje a su grado de conocimiento del castellano o traduciendo las preguntas no entendidas al inglés o francés.

\section{Análisis de los datos}

Tomando como referencia los criterios de fiabilidad de George y Mallery (1995), los coeficientes estimados (alpha de Cronbach) resultaron adecuados para las dimensiones relaciones mixtas (0.72), referentes culturales (0.68), normas (0.57), transnacionalidad (0.58) y psicosocial (0.62). Sin embargo, en la dimensión socioeconómica, el coeficiente obtuvo un valor más reducido (0.4), por ello, aunque se incluya en las tablas se prescinde de su análisis.

Con el propósito de identificar posibles diferencias en la percepción de los individuos sobre los constructos y las dimensiones del modelo, se llevaron a cabo análisis de la varianza (ANOVA de un factor). Se utilizó el estadístico F de Snedecor para medir el grado de significación global. También cabe señalar que la magnitud del efecto de las pruebas
(ME) es de 0.24 para la dimensión socioeconómica, 0.52 en relaciones mixtas, 0.46 en referentes culturales, 0.66 en normas, 0.33 en transnacionalidad y 0.38 en la dimensión psicosocial.

Por último, señalar que se han realizado análisis de regresión tomando como variable dependiente las diferentes dimensiones: factor socioeconómico, relaciones mixtas, referentes culturales, normas, transnacionalidad y factor psicosocial. En cuanto a las variables independientes, tal y como realizan estudios similares (véanse, por ejemplo, Aparicio \& Portes, 2014; Safi, 2006; 2008), se han utilizado variables sociodemográficas (sexo, edad, origen, creencias religiosas, etc.); individuales (generación, empleo, nacionalidad y estudios del padre, estructura familiar, etc.) y contextuales (características del vecindario, entre otras). No obstante, en la Tabla 2 (en apartado de resultados) solo se presentan aquellas variables que tuvieron una significación estadística de $p<0.05$ y $p<0.01$. Por último, cabe señalar que las variables nominales y ordinales independientes han sido transformadas en dummy.

\section{Resultados}

Siguiendo el principal objetivo de esta investigación, analizar la integración social de los jóvenes inmigrantes, se comprueba que el proceso de acomodación de los jóvenes inmigrantes no se lleva a cabo de forma homogénea. Más concretamente, en la dimensión relaciones mixtas $\left(F_{(4,154)}=4.9 ; p<\right.$ 0.001) los que mayor asimilación presentan son los latinoamericanos seguidos de los europeos del este y, en el último lugar, los africanos. En cuanto a los referentes culturales $\left(F_{(3,154)}=4.03 ; p<0.001\right)$, los africanos vuelven a ser los que menor asimilación presentan frente a los latinoamericanos. Respecto a las normas, los africanos vuelven a aparecer como el grupo que menos asimilación experimenta frente a los latinoamericanos $\left(F_{(4,154)}=7.5 ; p<0.001\right)$. En la dimensión transnacionalidad $\left(F_{(3,154)}=4.03 ; p<\right.$ 0.001 la situación se vuelve a repetir. Los latinoamericanos son los que menos contacto tienen con origen. Y, por último, en el factor psicosocial las diferencias son también significativas $\left(F_{(3,154)}=4.59\right.$; $p<0.001$ ); de manera que los latinoamericanos y 
europeos del este muestran las mayores dosis de asimilación, hasta el punto que los primeros doblan en su puntuación media a los africanos.

En suma, la Tabla 1 muestra, de manera general, que los jóvenes inmigrados no muestran importantes dosis de asimilación, puesto que el valor más alto de toda la tabla lo tienen los latinos en las relaciones mixtas $(M=2.6)$. Por su lado, el valor más bajo lo obtienen los africanos en normas y transnacionalidad $(M=0.8)$.

Ahora bien, el proceso de adaptación de los inmigrantes a la sociedad de llegada no solo se explica a través del origen, sino que actúan otra serie de variables de carácter estructural, contextual o individual. Para comprobar el peso de predicción de estas variables sobre los diferentes índices, se realizaron regresiones (Tabla 2).

En las relaciones mixtas se observa que está influenciada principalmente, de mayor a menor por: origen latino, nacionalidad española del cabeza de familia, segunda generación, nivel alto en competencias lingüísticas en español, mayoría de vecinos españoles y que el cabeza de familia posea un empleo de cuello blanco; con signo negativo, tener procedencia africana.

En cuanto a la dimensión referentes culturales se observa que, un nivel alto de competencias comunicativas en español, generación 2, 1.5 y 1.25 , llevar más de 5 años en España, pertenencia de la nacionalidad española del cabeza de familia, hombre, latinoamericano y ser católico afecta positivamente para alcanzar una asimilación en los patrones culturales de origen. Asimismo, el hecho de que el cabeza de familia no posea un empleo de cuello blanco o la edad afecta negativamente.

Por su lado, la dimensión normas se muestra, principalmente, influida por ser católico, segunda generación, que el progenitor tenga la nacionalidad española y posea estudios superiores, llevar más de 5 años en España, o pertenecer a la generación 1.5 y 1.25. Sin embargo, con signo negativo aparecen principalmente origen africano y latino y hombres. Esto es, los llegados de estos lugares se adscriben menos a las normas que los europeos del este y, de otro lado, las mujeres acatan más las normas de destino que los hombres.

En lo referente a la transnacionalidad, enumerados de mayor a menor peso explicativo aparecen, con influencia positiva: segunda generación, ser católico, llevar más de 5 años en España, nivel alto de competencias lingüísticas del español, estudios superiores del cabeza de familia, que la mayoría de los vecinos sean de nacionalidad española. Sin embargo, la generaciones 1.25 y 1.5 , que el cabeza de familia no posea un empleo de cuello blanco y no mostrar interés por los problemas y situación española afectan negativamente la integración en esta dimensión.

Y, por último, en la dimensión psicosocial se observa que pertenecer a la segunda generación, tener un origen latino, poseer un nivel alto de competencias lingüísticas en español, que el cabeza de familia posea la nacionalidad española y tenga estudios superiores, formar parte de una familia nuclear, ser hombre o que los vecinos sean de nacionalidad española presenta una avocación positiva con el índice.

\section{Discusión y conclusiones}

Los resultados obtenidos en el análisis de las diferentes dimensiones reafirman que los jóvenes inmigrados analizados muestran trayectorias de integración dispares en función de la dimensión

TABLA 1

Puntuaciones medias (desviación típica) de asimilación en las diferentes dimensiones por origen

\begin{tabular}{lcccccc}
\hline & Socioeconómico & $\begin{array}{c}\text { Relaciones } \\
\text { mixtas }\end{array}$ & $\begin{array}{c}\text { Referentes } \\
\text { culturales }\end{array}$ & Normas & Transnacionalidad & Psicosocial \\
\hline África & $1.8(1.1)$ & $1.3(1.1)$ & $1.6(0.9)$ & $0.8(0.8)$ & $0.8(0.9)$ & $0.9(0.9)$ \\
Europa del Este & $1.6(1)$ & $1.7(0.9)$ & $1.9(0.7)$ & $1.5(1.1)$ & $1.3(1.1)$ & $1.4(0.9)$ \\
Latinoamérica & $2.1(0.8)$ & $2.6(0.8)$ & $2.2(0.6)$ & $2.2(1.3)$ & $1.4(0.5)$ & $2.0(0.7)$ \\
\hline
\end{tabular}

Fuente: elaboración propia 
LA INTEGRACIÓN SOCIAL DE LOS HIJOS DE INMIGRANTES AFRICANOS, EUROPEOS DEL ESTE Y LATINOAMERICANOS: UN ESTUDIO DE CASO EN ESPAÑA

TABLA 2

Regresión de las dimensiones con variables demográficas, contextuales e individuales

\begin{tabular}{|c|c|c|c|c|c|c|}
\hline & Socioeconómica & $\begin{array}{l}\text { Relaciones } \\
\text { mixtas }\end{array}$ & $\begin{array}{l}\text { Referentes } \\
\text { culturales }\end{array}$ & Normas & Transnacionalidad & Psicosocial \\
\hline Edad & $-0.013 *$ & $-0.043 *$ & $-0.047 *$ & $0.03 *$ & $0.074 *$ & $-0.104 * *$ \\
\hline Sexo (hombre) & $-0.122 *$ & $0.021 *$ & $0.3 *$ & $-0.225^{*}$ & $0.077^{*}$ & $0.17 *$ \\
\hline Más de 5 años en España & $0.388 * *$ & $-0.046 *$ & $0.41 * *$ & $0.255^{*}$ & $0.351 * *$ & $0.137 *$ \\
\hline País de origen de África & $-0.116^{*}$ & $-0.573 *$ & $-0.014 *$ & $-0.719 *$ & $0.042 *$ & $0.239 *$ \\
\hline País origen Latinoamérica & $-0.014 *$ & $1.231^{*}$ & $0.225^{*}$ & $-0.371 *$ & $-0.068 *$ & $0.818^{*}$ \\
\hline Generación 2 & $0.938^{*}$ & $0.694^{*}$ & $1.221 *$ & $0.423 *$ & $0.806^{*}$ & $1.269 * *$ \\
\hline Generación 1.5 & $0.498^{*}$ & $0.276^{*}$ & $0.782 *$ & $0.243 *$ & $-0.323 *$ & $0.101 *$ \\
\hline Generación 1.25 & $0.472 *$ & $0.258 *$ & $0.651^{*}$ & $0.133 *$ & $-0.435 *$ & $0.084 *$ \\
\hline Mayoría de vecinos españoles & $-0.158 *$ & $0.403 * *$ & $0.002 *$ & $0.026^{*}$ & $0.17 *$ & $0.144^{*}$ \\
\hline $\begin{array}{l}\text { Empleo de cuello blanco del } \\
\text { cabeza de familia }\end{array}$ & $0.214^{*}$ & $0.282 *$ & $-0.071 *$ & $-0.077^{*}$ & $-0.278 *$ & $0.071^{*}$ \\
\hline Estructura familiar nuclear & $0.311^{*}$ & $0.106^{*}$ & $0.054^{*}$ & $-0.067 *$ & $0.001 *$ & $0.285 * *$ \\
\hline $\begin{array}{l}\text { Mostrar interés por los pro- } \\
\text { blemas españoles }\end{array}$ & $-0.031 *$ & $0.216^{*}$ & $0.065^{*}$ & $0.249 *$ & $-0.095^{*}$ & $-0.023 *$ \\
\hline $\begin{array}{l}\text { Nacionalidad española del } \\
\text { cabeza de familia }\end{array}$ & $0.55^{* *}$ & $0.703 * *$ & $0.247^{*}$ & $0.689 * *$ & $0.127 *$ & $0.32 *$ \\
\hline $\begin{array}{l}\text { Creencias religiosas (cató- } \\
\text { lica) }\end{array}$ & $0.078^{*}$ & 0.024 & $0.193 *$ & $1.524^{*}$ & $0.615^{*}$ & $-0.066^{*}$ \\
\hline $\begin{array}{l}\text { Nivel alto de competencias } \\
\text { lingüísticas en español }\end{array}$ & $0.324 *$ & $0.563^{*}$ & $1.228 * *$ & $0.208 *$ & $0.276^{*}$ & $0.491^{*}$ \\
\hline $\begin{array}{l}\text { Estudios superiores del cabe- } \\
\text { za de familia }\end{array}$ & $0.273^{*}$ & $0.215^{*}$ & $0.052 *$ & $0.328 *$ & $0.176^{*}$ & $0.291^{*}$ \\
\hline $\begin{array}{l}\text { Coeficiente de correlación } \\
\text { múltiple }\end{array}$ & 0.39 & 0.52 & 0.5 & 0.45 & 0.4 & 0.44 \\
\hline
\end{tabular}

$*_{p}<0.05$. **p $<0.01$.

Fuente: elaboración propia

analizada (socioeconómica, relacional, cultural, normas, transnacionalidad y psicosocial) y que, además, el origen y la generación se han demostrado importantes en dicho proceso de integración.

En cuanto a las relaciones mixtas y los referentes culturales los que mayor asimilación presentan son los latinoamericanos y europeos del este, frente a los africanos. Esto se explica por varios motivos: uno, a las mayores posibilidades de interacción debido a las similitudes culturales, especialmente definidas por el idioma y la religión. El primero, el idioma, es compartido con los latinos y tiene un tronco común para gran parte de los países del este. Con las creencias religiosas se repite la situación. Sin embargo, las distancias se hacen más agudas con los musulmanes africanos, puesto que esta creencia es un elemento que apenas experimenta grandes cambios en destino, por lo menos en las primeras generaciones (Moreras, 1999). Más aún, es el principal instrumento de reidentificación para estos grupos poblacionales. Sin embargo, el Islam es considerado por la sociedad y cultura española como algo esencialmente contrario a sus valores; de ahí que se les exija a los musulmanes la plena adhesión a los valores del país receptor, más que a los llegados de otros países no islámicos, y, al no producirse plenamente esta asimilación se genera un cierre identitario que conlleva a la creación de una subcultura al margen de la dominante. Dicho de otro modo, los altos niveles de prejuicio o rechazo por parte de los autóctonos genera el deseo de exclusión, como es el caso de los africanos (Navas et al., 2004). 
Además, los africanos a diferencia del resto de grupos se insertan residencialmente, sobre todo, en diseminados (Checa, 2007), lo que impide un contacto diario más allá del educativo con los autóctonos y por ende dificulta las relaciones intergrupales.

No obstante, Ioé et al. (2009, p. 23) comprueban que los africanos, para superar ese estigma de "inintegrables", reformulan su presentación sin negar su origen, diciendo: "soy africano pero no soy como (...), ni me comporto como otros". Se trata, así, de un intento de afirmar el origen a la vez que legitimar su identidad en el país de destino, separándose del estereotipo que los autóctonos tienen sobre el conjunto (fundamentalistas, marginalidad, delincuencia, etc.), estrategia que en la mayoría de las ocasiones solo es exitosa con sectores sociales no prejuiciosos.

Y además, a que los latinos, en primer lugar y los europeos del este, en segundo lugar, son los elegidos tanto por la población española como por las instituciones políticas (Izquierdo, 2009), al sentirlos como colectivos que no amenazan tanto la identidad nacional a partir de un viso analítico que se fundamenta en una supuesta homogeneidad ${ }^{6}$. Más aún, Carrasquilla y Echeverri (2003) y Echeverri (2005) comprueban, a través de las narrativas de los jóvenes latinoamericanos, que se están modificando (re-editando) sus identidades en el nuevo contexto, produciéndose una tendencia a una identificación supranacional o heteroidentidad, que no choca con la nacional; estrategia que resulta de la conjunción de la identidad objetivamente atribuida y la que se

6 No obstante, desde el año 2003 esta situación ha cambiado algo. Con el asesinato de Ronny Tapias en Barcelona, vinculado a "bandas latinas", los medios de comunicación se hicieron eco de este y otros sucesos, dibujando una narrativa de peligrosidad y violencia. Esto es, los jóvenes procedentes de Latinoamérica pasaron de ser invisibles y vinculados, casi exclusivamente, a sus países de origen a ser clasificados en una identificación más generalista: "jóvenes latinos" o, como diría Echeverri $(2005,2012)$ para explicar dicho proceso: "son diez horas de viaje y cinco que te meten encima”. De manera que su identidad ha sido transformada en el marco, sobre todo, de un nuevo contexto social y político, que la hace visible y diferente. Situación parecida está ocurriendo, más recientemente, con los procedentes de Europa del Este, la aparición de noticias que vincula a personas llegadas desde esos países con prostitución, tráfico de armas y grupos de delincuencia organizada está desembocando en una unicidad construida socialmente. asume subjetivamente, tras un proceso de oposición y complementariedad (Ioé et al., 2009).

Por su lado, la dimensión normas, la cual representa una medida de la "distancia sociocultural" entre los sistemas de valores de las sociedades estudiadas y la de recepción, o incluso, de modernidad, como sostiene Safi (2008), muestra que los procedentes de los países africanos vuelven a ser los menos asimilados. Tanto investigaciones internacionales (véase Crul \& Vermeulen, 2003) como nacionales (véase, Portes et al., 2010) resaltan que los procedentes de países más desarrollados tienen menos distancias socioculturales con el lugar de llegada, frente a los procedentes de países con un estadio de desarrollo económico inferior. Incluso más, Aparicio y Portes (2014) apuntan que el capital humano de los padres y las estructuras familiares en las que se educan los hijos, sumados al contexto de recepción que se encontraron los padres por razón de nacionalidad y el empleo que desempeñan en el mercado laboral, que determina el salario y la posibilidad de invertir en los hijos, diseña las expectativas de los hijos. De manera que atendiendo a la realidad, los africanos son quienes peores condiciones presentan. Por eso, se explica que los primeros manifiesten mayores aspiraciones educativas o reconozcan el papel que tiene la mujer en el ámbito laboral fuera del hogar.

De igual modo, la asimilación de normas está estrechamente relacionada con las motivaciones que llevaron al proceso migratorio, bien de sus padres o de los propios jóvenes y de la realidad experimentada. Puesto que la imagen y la realidad definen la integración (Carrasquilla \& Echeverri, 2003); o lo que es igual, el fracaso económico y social, así como las expectativas incumplidas, genera entre los inmigrados -jóvenes también- la imposibilidad de cerrar el proyecto migratorio, perviviendo una idea de retorno o nueva migración que no ayuda a asumir como propias las normas de origen (número de hijos, expectativas educativas o papel de la mujer en el mercado laboral, por ejemplo).

Aunque las "segundas y siguientes generaciones" podrían provocar una ruptura con la idea temporal de la migración, la quiebra de expectativas, como se ha apuntado, y la transnacionalidad mantienen 
vivo el proceso migratorio. Esta vez, el colectivo africano es el que más puntuación alcanza en las prácticas transnacionales. Debido a sus malas condiciones laborales y residenciales, sumado a altas dosis de irregularidad, impide un proceso de reagrupación familiar, lo que favorece el continuo contacto con su origen. Este dato, conjugado con los resultados de las dimensiones anteriores, respalda la idea de que el transnacionalismo puede dificultar la asimilación (Vertovec, 2004).

Sin embargo, los latinos y europeos del este presentan una actividad transnacional más débil y de hechos ocasionales que los africanos -fruto, entre otras cosas, de una reagrupación familiar más completa y/o lejanía al país de origen-. Y cuando los sujetos participan dentro de esos campos transnacionales, sus prácticas se presentan de manera más emocional. Dicho de otro modo, Echeverri (2011; 2012) sostiene que si bien muchos inmigrantes latinos tienen entre sus formas de estar el origen (comer alimentos de origen, hablar con familiares que no migraron, orar, etc.) en sus formas de pertenecer (identificarse conscientemente con una la etnicidad de partida) es más diluida, mestiza o híbrida. De manera que la identificación se basa más en determinadas prácticas culturales en función de redes familiares y afectivas a nivel micro que en compromiso y participación macro. Por tanto, se pueden presentar como actores sociales que participan más en el contexto de llegada, especialmente si tienen la doble nacionalidad.

Por último, en la dimensión psicosocial los africanos vuelven a ser los menos asimilados. Basta con recordar que para este colectivo la población nacional prefiere su exclusión (Navas et al., 2004). Y al manifestarse episodios de discriminación, promueven una adaptación psicosocial negativa y, en consecuencia, una menor autoestima (véase, Portes et al., 2012). Cuestión que solo se minimiza si el africano es nacido en España, puesto que estos no solo se van a identificar como españoles, sino también ofrecen una valoración más positiva a la hora de evaluar su integración.

De igual modo, tal y como vimos a partir de la regresión, existen también otras variables que inciden en este proceso: sobre todo, las referidas al capital humano y social. En el primero, cabe señalar la generación. De manera general, los inmigrados pertenecientes a la segunda generación presentan mayores dosis de asimilación en todas las dimensiones. Así lo muestran todos los estudios realizados tanto en el ámbito nacional como internacional. En otras palabras, haber nacido en España y/o llevar mucho tiempo en destino facilita más adscribirse a todos los patrones que presenta la mayoría de la población autóctona.

De igual modo, se resalta la importancia que tienen las características de los padres a la hora de diseñar la trayectoria de integración de los hijos. En este estudio se demuestra que un nivel de estudios elevado, dominio de competencias lingüísticas e incluso disfrutar de nacionalidad española por parte de los padres se convierten en instrumento claro de consonant acculturation. Más concretamente, cuanto mayor es el capital humano de los padres mayores dosis de asimilación a los patrones de los autóctonos (Portes, 1995). Asimismo, encontramos estudios que al igual que el presente ponen de relieve esta asociación positiva: Portes et al. (2010) revelan, para los jóvenes inmigrantes asentados en Madrid, que cuando sus padres tienen un importante capital humano, estos presentan aspiraciones y expectativas de futuro más ambiciosas que las exteriorizadas por personas cuyos padres alcanzan menor formación. No obstante, Aparicio y Portes (2014) también han comprobado que en el marco de la actual crisis económica española las expectativas de los padres con éxito económico y capital humano elevado son más altas que las metas y esperanzas marcadas por sus propios hijos debido a la realidad presente. Incluso más, como señalan Franzé (2003) y Franzé, et al. (2010), aunque se hayan obtenido ciertos niveles educativos, bien en origen o en destino, las necesidades del mercado laboral y las políticas segregadoras y excluyentes les han impedido acceder a empleos de calidad y cualificación -lo que sabía no vale-, lo que hace que los jóvenes se vuelvan más conformistas.

Si bien es cierto que la crisis económica también ha calado fuerte en la provincia de Almería, sus efectos en el sector agrícola - principal fuente de empleo de los inmigrados- ha sido menor. De 
ahí, que en este trabajo, se ha podido comprobar que, aun no presentando grandes niveles de asimilación económica, algunos jóvenes inmigrados se adscriben a pautas culturales o normas españolas; incluso más, aquellos jóvenes que presentan una dissonant acculturation sirven de muestra para otros inmigrantes o compatriotas sobre todo en la trayectoria educativa.

En segundo lugar, el capital social se convierte también, como muestran los datos, en una herramienta fundamental a la hora de diseñar la acomodación de los inmigrados en destino. Especialmente, toma importancia, para el presente caso, residir en lugares con mayoría de personas de nacionalidad española. En otras palabras, los grupos menos segregados, caso de los latinos -frente a los africanos- tienen más amigos nacionales lo que les facilita no solo el contacto intergrupal, sino también redes para acceder a mejores trabajos? ${ }^{7}$ Portes y Landolt (1996) también observaron que en aquellas comunidades o grupos que están aislados social y residencialmente sus redes quedan circunscritas a los coétnicos, y, por tanto, el desarrollo económico y social de sus descendientes será similar al experimentado por ellos (consonant assimilation). Gualda (2010), para la provincia de Huelva, también comprueba la existencia de una correlación positiva entre las variables tener muchos amigos españoles, sentirse integrado en la sociedad de acogida y manifestar deseos de intervenir en la vida social de destino. De manera que los sujetos que presentan déficits de apoyo social son los que manifiestan peores sentimientos hacia los autóctonos y su situación en el país de llegada.

En suma, varias son las conclusiones generales que se pueden extraer de este trabajo, a saber: (1) a los procedentes de países con características raciales, religiosas, etc. que más distan de las que

7 No obstante, Carrasquilla y Echeverri (2003) muestran que cuando los jóvenes latinos vienen directamente a trabajar las relaciones con los nacionales solo se circunscribe al centro de empleo, no presentándose relaciones intergrupales más allá de dicho ámbito. Incluso más, para los llegados a través de la reagrupación familiar e insertos en el sistema educativo español tampoco tienen la garantía de ampliar su capital social, puesto que, en no pocas ocasiones, en la escuela y su entorno también se reproducen los mecanismos de exclusión. tienen los autóctonos les persigue una tendencia a la exclusión; "los otros" son más segregados y, por tanto, presentan menor integración en la vida social. (2) Las características y aptitudes de los padres son claves a la hora de diseñar la trayectoria de acomodación de los hijos en las diferentes dimensiones. Más concretamente, cuanto mayor es el capital humano y social de los padres mayores dosis de asimilación a los patrones de los autóctonos. (3) Los pertenecientes a la segunda generación pura son los que manifiestan una mayor asimilación de los patrones culturales y relacionales del municipio con respecto a los demás sujetos. De ahí que los nacidos en su país de origen tienen expectativas educacionales inferiores a los nacidos en el país receptor. Incluso más, los que llegan de países económicamente más desarrollados muestran mayores aspiraciones y revelan puntuaciones superiores de asimilación en las dimensiones estudiadas. (4) Los hombres son los que mayor integración presentan en todas las dimensiones excepto en la dimensión normas. (5) Cuanto mejor se siente el individuo en el país de acogida mejor es su asimilación en el mismo. (6) Las trayectorias de integración de los jóvenes inmigrados dependen mucho del contexto de recepción, el cual muestra importantes porciones de fragmentación. De manera que el diseño de las políticas de integración toma una importancia notable. Tal y como se recoge en otros trabajos (Izquierdo, 2009) los latinoamericanos son los "elegidos". De ahí la imposibilidad de encontrar estrategias idénticas por parte de los inmigrados, puesto que la estructura de oportunidades se manifiesta de formas diferentes. Incluso más, debido a que las situaciones y experiencias son muy diversas, las estrategias de incorporación configuran múltiples escenarios, por tanto, es acertado hablar de pluralismo fragmentado.

\section{Referencias}

Alba, R. D. (2005). Bright vs blurred boundaries: Second-generation assimilation and exclusion in France, Germany and the United States. Ethnic and Racial Studies, 28(1), 20-49. 


\section{LA INTEGRACIÓN SOCIAL DE LOS HIJOS DE INMIGRANTES AFRICANOS, EUROPEOS}

DEL ESTE Y LATINOAMERICANOS: UN ESTUDIO DE CASO EN ESPAÑA

Alba, R. D., \& Nee, V. (1997). Rethinking assimilation: Theory for a new era of immigration. International Migration Review, 31(4), 826-874.

Aparicio, R. (2007). Las “segundas generaciones" en España ¿Qué movilidad social? En J. J. Igartua \& C. Muñiz (Eds.), Medios de comunicación, inmigración y sociedad (pp. 311-341). Salamanca: Universidad de Salamanca.

Aparicio, R., \& Portes, A. (2014). Crecer en España. La integración de los hijos de inmigrantes. Barcelona: La Caixa.

Arjona, A., Checa, F., \& Belmonte, T. (2011). Biculturalismo y segundas generaciones. Integración social, escuela y bilingüismo. España: Icaria.

Carrasquilla, M., \& Echeverri, M. (2003). Los procesos de integración social de los jóvenes ecuatorianos y colombianos en España: un juego identitario en los proyectos migratorios. Estudios de Juventud, $60,89-100$.

Carrera, S. (2006). Programas de integración para inmigrantes: una perspectiva comparada en la Unión Europea. Migraciones, 20, 37-73.

Checa, J. C. (2007). Viviendo juntos-aparte. La segregación residencial de los africanos en Almería. Barcelona: Icaria.

Checa, J. C., \& Arjona, A. (2009). La integración de los inmigrantes de "segunda generación” en Almería: un caso de pluralismo fragmentado. Revista Internacional de Sociología, 67(3), 701-727.

Colectivo Ioé, Actis, W., De Prada M. A., \& Pereda, C. (2009). Towards a social construction of a European youth: the experience of inclusion and exclusion in the publicsphere among second generation migrated teenagers. Informe TRESEGY (N.o 029105). http:// www.colectivoioe.org/uploads/

89b9a2e86010571f2c6c4d8e180344e3510f82ac.pdf

Crul, M., \& Vermeulen, H. (2003). The second generation in Europe. International Migration Review, 37(4), 965-986.

Echeverri, M. (2005). Fracturas identitarias: migración e integración social de los jóvenes colombianos en España. Migraciones Internacionales, 3(1), 141-164.

Echeverri, M. (2011). Sujetos políticos y actores sociales transnacionales: reconfiguración de las identidades y vínculos políticos de los y las jóvenes colombianas en migración. Geopolítica(s), 2(2), 283-311.

Echeverri, M. (2012). "Nosotros no migramos por billete": jóvenes colombianos en migración, conflicto armado y violencias. Metapolítica, 16(76), 52-61.

Franzé, A. (2003). Lo que sabía no valía: escuela, diversidad e inmigración. Madrid: Consejo Económico y Social.

Franzé, A., Moscoso, M., \& Calvo, A. (2010). Donde nunca hemos llegado. Alumnado de origen latinoamericano: entre la escuela y el mundo laboral. En GIIM (Coord.), Familias, niños, niñas y jóvenes migrantes. Rompiendo estereotipos (pp. 123-138). Madrid: IEPALA.

García, I. (2003). Los hijos de inmigrantes extranjeros como objeto de estudio de la sociología. Anduli, 3, 27-46.

García, I. (2008). Herederos de la condición inmigrante: adolescentes y jóvenes en familias madrileñas de origen extranjero. Madrid: UNED.

George, D., \& Mallery, P. (1995). SPSS/PC + Step by: A simple guide and reference. Belmont: Wadsworth Publishing Company.

Gualda, E. (2007). Segunda generación y adolescentes y jóvenes inmigrantes: el caso de Huelva. En E. Gualda \& I. Rodríguez (Dirs.), Infancia y juventud en las migraciones internacionales (pp. 51-70). Madrid: Exlitris.

Gualda, E. (2008). Integración social de adolescentes y jóvenes inmigrantes e hijos de inmigrantes en Huelva. Huelva: Universidad de Huelva.

Gualda, E. (2010). La segunda generación de inmigrantes en Huelva: Estudio HIJAI. Valencia: Junta de Andalucía.

Gordon, M. (1964). Assimilation in American life: The role of race, religion and national origins. New York: Oxford University Press.

Hartmann, D., \& Gerteis, J. (2005). Dealing with diversity: Mapping multiculturalism in sociological terms. Sociological Theory, 32(2), 218-240.

Izquierdo, A. (2009). El modelo de inmigración y los riesgos de exclusión. Madrid: Foessa.

Levitt, P., \& Glick Schiller, N. (2004). Perspectivas internacionales sobre migración: conceptualizar la simultaneidad. Migración y Desarrollo, 3, 191-229. 
Moreras, J. (1999). Musulmanes en Barcelona. Espacios y dinámicas comunitarias. Barcelona: Cidob.

Navas, M., Pumares, P., Sánchez, J., García, M., Rojas, A., Cuadrado, I., Asensio, M., \& Fernández, J. S. (2004). Estrategias y actitudes de aculturación de los inmigrantes en la provincia de Almería. Sevilla: Junta de Andalucía.

Navas, M., Rojas, A., \& García, M. (2011). Concordancia entre actitudes y percepciones de aculturación de la población autóctona hacia los inmigrantes. Anales de Psicología, 27(1), 186-194.

Park, R. (1928). Human migration and the marginal man. American Journal of Sociology, 33, 881-893.

Pedone, C. (marzo, 2007). Los hijos y las hijas de la migración ecuatoriana: lecturas transnacionales de los cambios familiares. Ponencia presentada en el V Congreso sobre la Inmigración en España. Migraciones y Desarrollo Humano, Universitat de Valencia, CEIM, Valencia.

Portes, A. (1995). Children of immigrants: Segmented assimilation and its determinants. The Economic Sociology of Immigration. New York: Russell Sage Foundation.

Portes, A., Aparicio, R., Haller, W., \& Vickstrom, E. (2010). Progresar en Madrid: aspiraciones y expectativas de la segunda generación en España. Revista Española de Investigaciones Sociológicas, 134, 55-86.

Portes, A., \& Landolt, P. (1996). The downside of social capital. The American Prospect, 26(26), 18-21.

Portes, A., Celaya, A., Vickstrom, E., \& Aparicio, R. (2012). ¿Quiénes somos? Influencia de los padres en la identidad y la auto-estima de los jóvenes de segunda generación en España. Revista Internacional de Sociología, 70(1), 9-37.

Portes, A., \& Rumbaut, R. (2010). América inmigrante. Barcelona: Antropos.

Safi, M. (2006). Le processus d'intégration des immigrés en France: inégalités et segmentation. Revue Francaise de Sociologie, 47, 3-48.

Safi, M. (2008). The immigrant integration process in France: Inequalities and segmentation. Revue Francaise de Sociologie, 49, 3-44. doi: 10.3917/ rfs.495.0003

Safi, M. (2010). Immigrants' life satisfaction in Europe: Between assimilation and discrimination. European Sociological Review, 26(2), 159-176.

Thomson, M., \& Crul, M. (2007). The second generation in Europe and the United States: How is the transatlantic debate relevant for further research on the European second generation? Journal of Ethnic and Migration Studies, 33(7), 1025-1041.

Tribalat, M. (1996). De l'immigration à l'assimilation: enquête sur les populations d'origine étrangère en France. Paris: La Découverte.

Vertovec, S. (2004). Migrant transnationalism and modes of transformation. International Migration Review, 38(3), 970-1001.

Zapata, R. (Coord.). (2009). Política y gobernabilidad de la inmigración en España. Barcelona: Ariel.

Zhou, M. (1997). Segmented assimilation: issues, controversies and recent research on the new second generation. International Migration Review, 31 (4), $975-1008$ 